Table 1. Observed infrared LiF spectrum of butatriene: gas $10 \mathrm{~cm}$, equilibrium temperature $-19^{\circ} \mathrm{C}$.

\begin{tabular}{|c|c|c|}
\hline $\begin{array}{l}\text { Band centra } \\
\left(\mathrm{cm}^{-1}\right)\end{array}$ & $\underset{\left(\mathrm{cm}^{-1}\right)}{\operatorname{Maxima}}$ & Intensity \\
\hline \multirow{3}{*}{1607} & / 1599 & vs \\
\hline & $\{1615$ & vs \\
\hline & 1687 & $\mathbf{s}$ \\
\hline \multirow{4}{*}{1711} & / 1702 & vs \\
\hline & $\{1719$ & vs \\
\hline & 1736 & $\mathbf{s}$ \\
\hline & 1969 & $w$ \\
\hline \multirow{6}{*}{2034} & f 2026 & $\mathbf{s}$ \\
\hline & $\{2041$ & $\mathbf{s}$ \\
\hline & 2475 & $w$ \\
\hline & 2889 & $w$ \\
\hline & 2939 & w \\
\hline & 2955 & $w$ \\
\hline \multirow{9}{*}{3001} & / 2994 & vs \\
\hline & 3007.5 & vs \\
\hline & $(3030)$ & fine \\
\hline & \begin{tabular}{|l|}
$\mathbf{3 0 4 0}$ \\
$\mathbf{3 0 4 7}$
\end{tabular} & structure \\
\hline & 3059 & $\mathrm{~s}$ \\
\hline & 3066 & \\
\hline & 3076 & \\
\hline & 3087 & \\
\hline & 3095 & \\
\hline \multirow{14}{*}{3059} & 3105 & \\
\hline & 3115 & \\
\hline & 3123 & fine \\
\hline & 3132 & structure \\
\hline & 3142 & \\
\hline & 3152 & \\
\hline & 3160 & \\
\hline & 3170 & \\
\hline & 3178 & \\
\hline & 3448 & $\mathbf{w}$ \\
\hline & 4082 & $w$ \\
\hline & 4141 & w \\
\hline & 4484 & $\mathbf{w}$ \\
\hline & 4651 & $w$ \\
\hline
\end{tabular}

1. Stoicheff, B. P. Can. J. Phys. 35 (1957) 837.

2. Almenningen, A., Bastiansen, $O$. and Trætteberg, M. Acta Chem. Scand. 15 (1961) 1557.

3. Schubert, W. M., Liddicoet, T. H. and Lanka, W. A. J. Am. Chem. Soc. 76 (1954) 1929.

4. Eggers, Jr., D. F. Private communication (1958).

5. Klæboe, P. and Cyvin, S. J. To be published.

Received July 22, 1963.

\section{Effect of Irradiation Temperature on the Yield of Solute Radicals in Frozen Aqueous Solutions}

\author{
A. P I H L, T. SA N N E R * and \\ T. H E N I K S E N *
}

Norsk Hydro's Institute for Cancer Research, Montebello, Norway

In the present communication data are reported on the effect of the irradiation temperature on the efficiency of the indirect action of ionizing radiation.

When solutions are exposed to ionizing radiation, free radicals are induced in the solvent as well as in the solute. At $77^{\circ} \mathrm{K}$ or lower, there is little or no interaction between solvent radicals and solute molecules. Under these conditions the solute radicals, as revealed by electron spin resonance (ESR) spectroscopy, are formed predominantly by direct action. ${ }^{1-3}$ When frozen aqueous solutions are heat-treated after irradiation, the radicals induced in the water disappear in the temperature range $100^{\circ}$ to $130^{\circ} \mathrm{K}$, largely by recombination reactions. Some of the radicals will, however, interact with the solute molecules with the result that radiation energy is transferred to the solute. The extent of this indirect effect in frozen aqueous solutions irradiated at $77^{\circ} \mathrm{K}$ is small compared to that observed after irradiation in the liquid state..$^{3,4}$ Although the state of the solution is the most important factor in this respect, ${ }^{5,6}$ the possibility exists that the irradiation temperature as such may have a significant influence on the interaction of water radicals with solute molecules.

Frozen aqueous solutions of $\mathrm{DL}_{-}-\alpha$-alanine were irradiated in vacuum with $\mathrm{X}$-rays at different temperatures in the range $77^{\circ}$ to $195^{\circ} \mathrm{K}$. During the exposure (104 min) secondary reactions will occur in the solvent as well as in the solute. In order to eliminate possible differences in the extent of the secondary reactions at the different temperatures used, all samples were heat-treated for $3 \mathrm{~min}$ after the exposure. A temperature was chosen $\left(250^{\circ} \mathrm{K}\right)$ that was appreciably higher than the highest irradiation temperature. The ESR spectra were recorded at $77^{\circ} \mathrm{K}$. The

* Fellow of the Norwegian Cancer Society. 


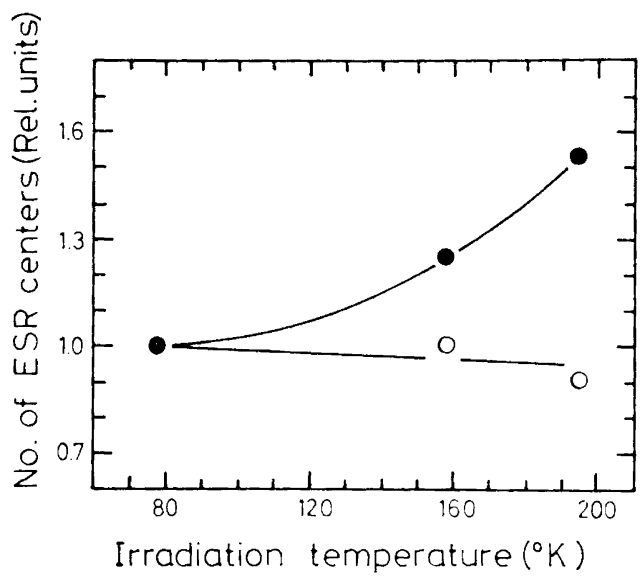

Fig. 1. The effect of the irradiation temperature on the observed yield of ESR centers in DL-a-alanine. The samples were irradiated in vacuum with $\mathrm{X}$-rays $(104 \mathrm{~min}$ at a dose rate of $4600 \mathrm{R} / \mathrm{min}$ ). After the irradiation the samples were heat-treated as described in the text. All spectra were recorded at $77^{\circ} \mathrm{K}$. - alanine, $10 \%$ solution; $O$, alanine, dry state.

spectrometer used operates at $9200 \mathrm{Mc} / \mathrm{sec}$ and uses $110 \mathrm{kc} / \mathrm{sec}$ modulation frequency. The spectra, following phase sensitive detection, yield the first derivative of the absorption curves. The procedure for obtaining quantitative data has been described elsewhere. ${ }^{7}$

The qualitative spectra observed immediately after the irradiation differed with the irradiation temperature. However, the spectra observed after the heat-treatment demonstrated that the same type of radicals were eventually present whether the irradiation was carried out at $77^{\circ}$, $158^{\circ}$, or $195^{\circ} \mathrm{K}$. Also, the same radicals were present whether the alanine was irradiated in solution (10\% by weight) or in the dry state. The quantitative results demonstrate (Fig. 1) that when alanine was irradiated in solution the observed number of solute radicals increased appreciably with increasing temperature.

The observed temperature effect on the yield of solute radicals could be due to several factors. An increase in the direct effect can not account for the results since the yield of alanine radicals was virtually unaffected by the temperature when alanine was irradiated in the dry state
(Fig. 1). The possibility that the results could be accounted for by a temperature effect on the number of water radicals available for interaction with solute molecules can not be excluded.

The most plausible explanation of the data seems to be that the efficiency of the interaction of water radicals with alanine molecules increases with increasing irradiation temperature. Reactions between alanine molecules and radicals induced in water presumably have higher energies of activation than radical-radical interactions. Thus, the latter ones predominated at low temperatures, in spite of the fact that in the $10 \%$ solution the probability for collisions between water radicals is much lower than the probability for collisions between radicals and solute molecules. Consequently, when frozen aqueous solutions are irradiated at $77^{\circ} \mathrm{K}$ and subsequently heat-treated most of the free radicals formed from water will disappear in recombination reactions before a temperature is reached which permits reactions with solute molecules to occur at a significant rate. When the temperature at the time of radical formation is higher, i.e. at higher irradiation temperatures, reactions resulting in the transfer of radiation energy from solvent to solute molecules will assume relatively greater importance. ${ }^{8}$

This work was supported by the Division of Radiological Health, Bureau of State Services, U.S. Public Health Service.

1. Henriksen, T. Radiation Res. 17 (1962) 158.

2. Henriksen, T., Sanner, T. and Pihl, A. Radiation Res. 18 (1963) 163.

3. Henriksen, T. J. Chem. Phys. 38 (1963) 1926.

4. Henriksen, T. in Abstracts of papers 2nd int. Congr. Radiation Research, Harrogate 1962. London, Silver End Documentary Publ., p. 21. See also Boag, Electron Spin Resonance in Biology, in Ebert, M. and Howard, A. Radiation Effects in Physics, Chemistry and Biology, North Holland Publ. Co., Amsterdam 1963.

5. Wood, T. H. and Taylor, A. L. Radiation Res. 7 (1957) 99.

6. Brustad, T. Radiation Res. In press.

7. Henriksen, T. and Pihl, A. Intern. $J$. Radiation Biol. 3 (1961) 351.

8. Henriksen, T. Electron Spin Resonance Studies on the Formation and Properties of Free Radicals in Irradiated Sulfur-Containing Substances. Oslo University Press, Oslo 1963.

Received August 28, 1963.

Acta Chem. Scand. 17 (1963) No. 7 